\title{
Decreased Visual Acuity
}

National Cancer Institute

\section{Source}

National Cancer Institute. Decreased Visual Acuity. NCI Thesaurus. Code C118714.

Diminished clarity of vision. 